\title{
Aditivos de secagem para concretos refratários: pó de alumínio e fibras poliméricas
}

\author{
(Drying additives for refractory castables: \\ aluminum powder and polymeric fibers)
}

\author{
R. Salomão ${ }^{1}$, L. R. M. Bittencourt ${ }^{2}$, V. C. Pandolfelli ${ }^{1}$ \\ ${ }^{l}$ Departamento de Engenharia de Materiais, Universidade Federal de S. Carlos \\ Rod. Washington Luiz, km 235, C.P. 676, S. Carlos, SP 13565-905 \\ ${ }^{2}$ Magnesita S.A., Praça Louis Ensch, Contagem, $M G$ \\ rflslm@gmail.com,vicpando@power.ufscar.br
}

\begin{abstract}
Resumo
Concretos refratários são usualmente materiais de baixas porosidade e permeabilidade. Devido a isso, a retirada da água adicionada às formulações durante a mistura deve ser feita de modo cuidadoso para minimizar os riscos de explosão e danos mecânicos envolvidos. Por outro lado, a crescente utilização de concretos refratários em revestimentos de calcinadores para a indústria de alumínio e o período de lucro cessante durante essa etapa do processamento desses materiais indica que programas de aquecimento otimizados possam se tornar um importante diferencial competitivo para as empresas. Na tentativa de conciliar esses aspectos, aditivos para facilitar o processo de secagem e torná-lo mais seguro foram desenvolvidos. Entre os principais, destacam-se o pó de alumínio, as fibras poliméricas convencionais e as de alto desempenho. Neste trabalho, são apresentados seus mecanismos de atuação e comparações em relação às condições que otimizam seu desempenho.

Palavras-chave: concretos refratários, aditivos de secagem, pó de alumínio, fibras poliméricas.
\end{abstract}

\begin{abstract}
Refractory castables are low porosity and permeability materials. Due to this, the first heat up must be carried out in a careful way in order to avoid the risks of explosive spalling and mechanical damages during the water withdrawn. On the other hand, the growing use of refractory castables in the aluminum industry, as calciners lining, and the lack of production during their placement indicate that optimized heating schedules may become an important competitive advantage to the companies. In order to join these two aspects, additives to easy the drying process and to make it safer were developed. These drying additives behave, generally, increasing the castable permeability in a more controlled way. The most important ones are the aluminum powder and the polymeric fibers. In the present work, their mechanisms and the most suitable processing condition for their use are presented.
\end{abstract}

Keywords: refractory castables, drying additives, aluminum powder, polymeric fibers.

\section{EVOLUÇÃO HISTÓRICA DO PROCESSO DE SECAGEM DE CONCRETOS REFRATÁRIOS}

Embora existam registros anteriores à era cristã da utilização de concretos e argamassas em construções (Êxodo, 5:7), seu uso em aplicações voltadas à indústria de refratários tornou-se comercialmente viável e se popularizou a partir da segunda metade do século XX [1]. Nas primeiras formulações descritas em trabalhos científicos, foram utilizados agregados de sílica, aluminas e hidróxidos de alumino de baixa pureza, argilas refratárias e cimentos de baixa refratariedade (principalmente, pelo elevado teor de silicato de cálcio) $[2,3]$. Sem as atuais tecnologias de agentes dispersantes e modelos de empacotamento de partículas, teores de água da ordem de 20-25\% peso eram necessários para misturar e transportar essas formulações. Adicionalmente, grandes quantidades de cimento eram empregadas para garantir propriedades mecânicas mínimas após a desmoldagem.

Por volta de 1964, vários trabalhos identificaram questões importantes referentes ao processo de secagem desses materiais $[4,5]$. Devido à baixa qualidade e granulometria grosseira das matérias primas utilizadas, ao elevado volume de água empregado na mistura e ao aquecimento gerado pela hidratação parcial das grandes quantidades de cimento empregadas, as estruturas geradas nessas condições eram muito porosas e permeáveis. Como consequiência, freqüientemente, a secagem ocorria tão rapidamente que os ligantes hidráulicos utilizados não tinham tempo de reagir com a água e fornecer resistência mecânica suficiente para a desmoldagem. Além disso, após a secagem, também se verificava a ocorrência de trincas e vazios causados pela má compactação das partículas. A combinação desses fatores gerava materiais com propriedades termomecânicas e 
refratariedade sob carga muito inferiores às da geração atual. Ainda que propiciassem maior liberdade de projeto e menor consumo de mão-de-obra e energia para a instalação, essas dificuldades fizeram com que, nas décadas seguintes, o consumo dos concretos refratários permanecesse significativamente abaixo dos refratários pré-moldados $[1,6]$.

Nas décadas de 1970 e 1980, após enfrentar um grave período de recessão, a indústria siderúrgica viu-se obrigada a realizar uma série de modificações conceituais em seu sistema de produção. Afetados por essa mudança de paradigma, os produtores de refratários também foram obrigados a se adaptar a essa nova realidade. Com a evolução no desenvolvimento desses materiais, os usuários alcançaram melhor desempenho, resultando na redução do consumo de refratários por tonelada de aço produzido e no aumento de seu valor agregado. Esse aumento de desempenho esteve relacionado a dois fatores principais [6]: o primeiro foi o desenvolvimento dos tijolos refratários de magnésia e magnésia-carbono entre 1985 e 1995. Comparando com outras classes de refratários, estas apresentam elevada refratariedade, resistência termo-mecânica e à corrosão, aliados a um custo competitivo; o segundo fator estava relacionado ao grande avanço na tecnologia de produção e instalação dos refratários monolíticos, graças ao emprego de matérias primas mais nobres e de novas técnicas de formulação e empacotamento, além da utilização de novos agentes dispersantes. A versatilidade desses novos materiais fez com que a relação de tendência de consumo entre monolíticos e os pré-moldados tradicionais se invertesse.

No entanto, após 1995 o número de patentes registradas sobre esses materiais vem sendo reduzido, ano após ano [6]. Esse fato indica que, embora funcionais e com bom desempenho, essas tecnologias atingiram seu limite de desenvolvimento. Deu-se lugar, portanto, às inovações menores ou não patenteáveis, enquanto aquelas de alto impacto permanecem ainda no estágio de pesquisa. Esse contexto favoreceu o desenvolvimento de aditivos de secagem para concretos refratários.

Ainda no que diz respeito à sua evolução, os concretos refratários tornaram-se materiais cada vez mais densos e menos permeáveis [7-9]. Essa condição mostrou-se fundamental para seu bom desempenho termo-mecânico e para à resistência à penetração de escórias, vapores corrosivos e metal líquido. Embora esse desenvolvimento tenha levado ao aumento de sua vida útil, um importante efeito colateral passou a ser observado: os programas de aquecimento inicial e secagem, que funcionaram adequadamente por vários anos, começaram a se tornar inadequados à medida que o número de explosões ou danos no material aumentava [9].

Trabalhos científicos identificaram a baixa permeabilidade desses novos materiais e os programas de aquecimento não otimizados como a responsáveis pela ocorrência de explosões $[7,8]$. Como a secagem de materiais nãorefratários é uma operação unitária bastante explorada, diversas ferramentas tradicionais de modelamento matemático e computacional foram direcionadas ao processamento de concretos [10]. Embora alguns trabalhos laboratoriais teóricos ou em peças pequenas e de geometria simples tenham alcançado algum sucesso, os modelos gerados não evoluíram para soluções utilizáveis na prática, devido à complexidade das peças e à dificuldade natural de controle preciso das muitas variáveis envolvidas, como umidade e temperatura ambiente e taxas de aquecimento.

Como tentativa paralela para a solução dos problemas do processo de secagem, vários trabalhos relataram a ação de aditivos que podiam modificar favoravelmente o comportamento de secagem dos concretos, principalmente, por meio do aumento controlado da porosidade e permeabilidade da estrutura [11-14]. A utilização desses aditivos de secagem representou um forte apelo tecnológico em relação à otimização de programas de secagem. Enquanto, estas podiam necessitar da aquisição de novos equipamentos e de modificações nas instalações industrias e, ainda assim, serem altamente específicas para uma única classe de materiais, a aditivação de secagem representava uma solução de maior robustez, praticidade e versatilidade. Facilmente incorporados sem grandes modificações nas formulações, os aditivos deveriam atuar adequadamente, com dependência mínima do tipo de formulação e do programa de secagem utilizados. Resultados bastante promissores foram alcançados com a adição de pó de alumínio e fibras poliméricas às formulações de concretos refratários, como será visto nas próximas seções.

\section{COMPORTAMENTO DE SECAGEM DE CONCRETOS REFRATÁRIOS}

Para compreender os mecanismos de atuação dos aditivos de secagem, inicialmente é necessário considerar algumas variáveis e as peculiaridades do comportamento de secagem dos concretos refratários. A adição de água às formulações de concretos refratários, por exemplo, é necessária por duas razões principais [15-16]: 1) promove uma mistura mais eficiente das diferentes matérias primas utilizadas, permitindo que possam ser transportadas e moldadas mais facilmente e 2) por meio de reações químicas com os ligantes hidráulicos, como os cimentos de aluminato de cálcio e aluminas hidratáveis, a água atua como componente da fase cementante, que garante as propriedades mecânicas mínimas ao material antes que as ligações cerâmicas sejam formadas na sinterização. Embora algumas formulações de concreto refratário sejam aplicadas sem água ou com outros veículos líquidos, como resinas poliméricas termofixas, aquelas de base aquosa apresentam maior praticidade, menores custos, podem ser mais facilmente transportadas e geram menor impacto ambiental em relação à liberação de voláteis tóxicos. Desse modo, pode-se entender a presença de água nesses materiais como necessária, porém sujeita a estudos que visem a redução de seus efeito deletérios durante a secagem.

A secagem pode ser definida com a remoção de água (ou outra substância líquida) de um meio ou material, pela 
aplicação de uma força motriz, proveniente de gradientes de pressão, de concentração ou térmicos, envolvendo a transferência simultânea de massa, energia e quantidade de movimento [17, 18]. Embora esse conceito seja generalista e aplicável a diferentes sistemas, processos e operações industriais que envolvem a retirada de água ou outros líquidos de meios sólidos, particulados ou líquidos, os aspectos teóricos e observações apresentadas a seguir serão direcionadas para a secagem de concretos refratários.

Em concretos refratários, a retirada da água ocorre principalmente através da porosidade aberta presente na matriz (canais muito numerosos, porém estreitos e tortuosos) e das interfaces permeáveis entre matriz e agregados (canais de baixa tortuosidade, mas em pequena quantidade), geradas por falhas de empacotamento devido às diferenças de tamanho de partícula (Fig. 1) [19-20]. Essa retirada é composta por vários estágios, diferenciados pelas forças motrizes e mecanismos de transporte envolvidos e suas cinéticas de reação. Suas principais características são

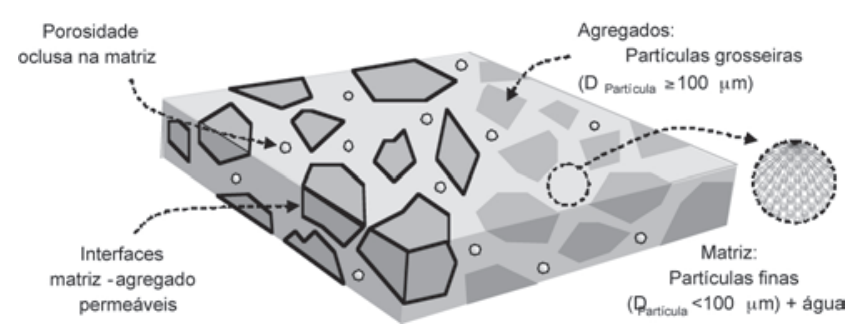

Figura 1: Canais permeáveis na estrutura de concretos refratários que contribuem para o processo de secagem (interfaces matrizagregado e porosidade da matriz).

[Figure 1: Permeable paths, in the refractory castables' structure that contributes to the drying process - matrix aggregates interfaces and porosity $[19,20]$.

esquematizadas nas Figs. 2 e 3, a seguir.

Nos momentos que antecedem o início da secagem, em geral, pode-se observar um filme contínuo de água que recobre a superfície do meio poroso (Fig. 2a) [18, 21]. Sua presença revela que a fração volumétrica de água presente no material foi suficiente para recobrir toda a área superficial das partículas presentes. É a partir da remoção desse filme que se inicia o processo de secagem.

O primeiro estágio denomina-se evaporação e envolve a retirada da água presente nas camadas mais próximas à superfície do material de forma adiabática (Figs. 2b, 2c e 3a) $[17,21]$. Como não há grandes obstáculos à remoção de água, sua velocidade é limitada pelas forças motrizes do processo (pressão parcial de vapor na atmosfera, temperatura e pressão ambientes). Uma vez removido o filme superficial, interfaces sólido/ar são geradas. Para reduzir a formação dessa nova interface, a tensão superficial da água leva à formação de meniscos nos espaços entre partículas na tentativa de manter a coesão do filme (Figs. 2b e 2c) [18]. Essa condição é altamente energética e gera forças de capilaridade capazes de trazer o fluido presente no interior da estrutura para a superfície. Dependendo de sua mobilidade, as partículas sólidas podem se aproximar para reduzir ainda mais a energia da superfície. Em concretos refratários, devido à elevada concentração de sólidos e à presença de ligantes, esse efeito de retração durante a secagem geralmente não é observado. O processo persiste enquanto as forças motrizes atuarem sob o material e enquanto houver equilíbrio entre a quantidade de água que é removida na superfície e aquela que migra do interior da estrutura. Esse equilíbrio faz com que a taxa de secagem permaneça estável durante todo o processo e é conhecido como período de taxa de secagem constante (PTSC) [18].

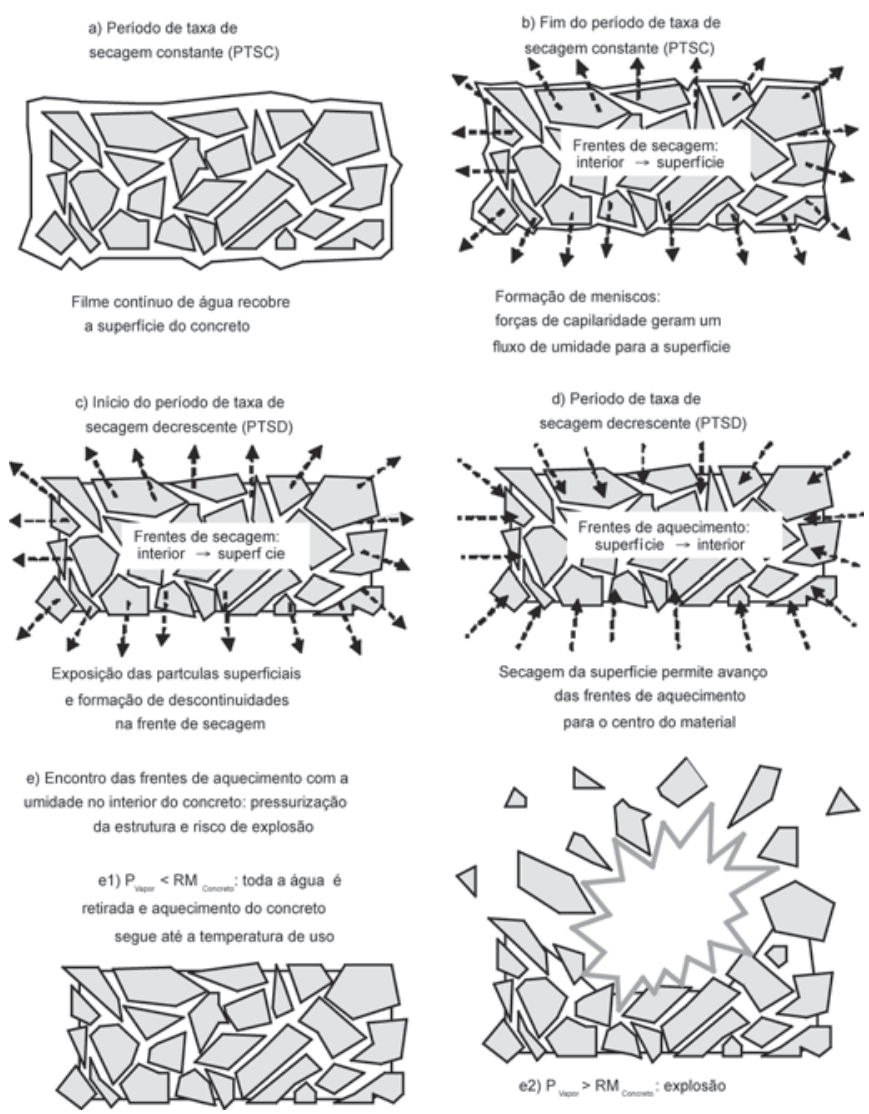

Figura 2: Estágios da secagem dos concretos refratários.

[Figure 2: Refractory castables' drying stages [18, 21].]

Porém, como a secagem de concretos refratários não é conduzida em condições estacionárias, mas sob aquecimento contínuo até temperaturas acima do ponto de ebulição da água, à medida que a temperatura se aproxima de $100{ }^{\circ} \mathrm{C}$ a pressão de vapor da água aumenta [21, 22]. Como conseqüência, a velocidade de secagem na superfície supera a de migração da água do interior da estrutura levando à formação de uma descontinuidade entre as camadas mais profundas e úmidas do material e sua superfície seca (Figs. 2c, 2d e 3a). A partir desse ponto, a transferência de água, que ocorria por meio do fluxo do fluido, passa a depender da 
difusão do vapor através dos canais permeáveis da estrutura. Essa diminuição gradual na taxa de secagem é conhecida como período de taxa de secagem decrescente (PTSD) [18].

Durante a vaporização da água a temperatura e a taxa de aquecimento na superfície de secagem são significativamente menores que a do ambiente (Fig. 3b). Isso ocorre devido à maior capacidade calorífica da água que absorve grandes quantidades de calor, tornando menos eficiente o aquecimento do meio sólido. Quando a secagem é conduzida sob aquecimento contínuo, esse fato adquire grande importância ao fim dos vários estágios de secagem. Nos períodos de taxas de secagem decrescentes, há menor quantidade de água presente entre as partículas sólidas da superfície e, portanto, mais calor pode ser absorvido por elas. Observa-se então uma taxa de aquecimento na superfície maior que a utilizada no ambiente de secagem (nos fornos, por exemplo), na tentativa de re-estabelecer o equilíbrio térmico do sistema [22]. Ao fim do primeiro
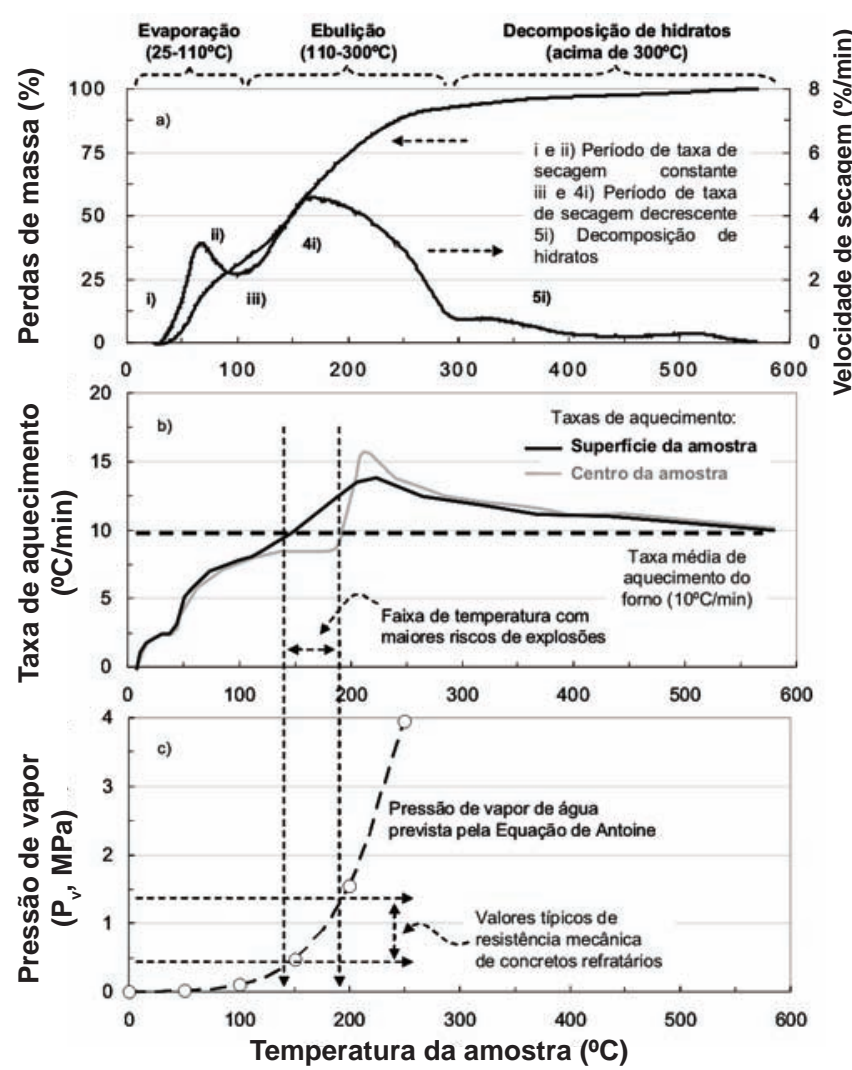

Figura 3: a) Termogravimetria dos estágios de secagem de concretos refratários; b) taxa de aquecimento da superfície e centro de concretos refratários durante os vários estágios de secagem e c) evolução da pressão de vapor da água em função da temperatura (equação de Antoine) e a faixa correspondente de resistência mecânica típica para concretos refratários verdes (medida por compressão diametral) [21, 22].

[Figure 3: a) Thermogravimetry of the castable drying stages; $b$ ) heating rate at the surface and at the center of castable samples during the drying stages and c) water vapor pressure as a function of the temperature (Antoine equation) and the castable correspondent typical mechanical strength levels [21, 22].] estágio de secagem, a temperatura da superfície tende a subir até por volta de $100-110{ }^{\circ} \mathrm{C}$ e, a partir desse ponto, a taxa de aquecimento se mantém aproximadamente constante até que toda água que possa ser retirada por evaporação seja removida. Uma vez que a superfície seque, uma nova frente de aquecimento penetra no material até encontrar suas camadas mais internas ainda úmidas (Fig. 2d) [21]. Devido ao maior gradiente térmico existente entre a água e a temperatura do concreto, a taxa de aquecimento da superfície e a velocidade de secagem começam a aumentar novamente. A força motriz para o fluxo de massa para a superfície passa a ser a pressurização do vapor e inicia-se o segundo estágio de secagem: a ebulição [21, 22]. Comparando-se as velocidades de secagem envolvidas nos dois primeiros estágios, a da ebulição é significativamente maior já que não depende das condições do ambiente e sim da pressão de vapor da água a uma certa temperatura e da taxa de aquecimento utilizada [17, 21]. Esses fatores são os principais responsáveis pelos elevados riscos de explosão durante a secagem dos concretos. Como a formação de vapor pode ocorrer rapidamente, dependendo da taxa de aquecimento utilizada, e se localiza a uma certa profundidade da superfície do material (Fig. 2d), nem sempre há um balanço favorável entre a quantidade de vapor formada e aquela que é retirada pela superfície. Esse fato, aliado à baixa porosidade das estruturas dos concretos refratários, com canais permeáveis estreitos e tortuosos, e à considerável espessura das peças produzidas com esses materiais, freqüente provoca a formação de acúmulos de vapor pressurizado [7, 9, 21, 22].

A pressurização do sistema água líquida/vapor permite que a água possa ser aquecida a temperaturas acima do ponto de ebulição normal registrado à pressão ambiente (1 atm), analogamente ao que ocorre em uma panela de pressão. Devido a isso, de modo distinto ao observado no estágio de evaporação, durante a ebulição, a temperatura na frente de secagem apresenta uma taxa de aquecimento bastante elevada durante o processo, entrando num ciclo aquecimento/pressurização/aquecimento. Essa relação de dependência entre temperatura e pressão de vapor para um sistema água líquida/vapor confinado em um ambiente fechado ou, de forma aproximada, em uma condição onde a saída do vapor é dificultada pode ser descrita pela lei de Antoine (Fig. 3c):

$$
\mathrm{P}_{\mathrm{V}}=\exp (\mathrm{A}-(\mathrm{B} / \mathrm{T}+\mathrm{C}))
$$

onde $\mathrm{P}_{\mathrm{v}}$ é a pressão de vapor da água (MPa), $\mathrm{T}$ é a temperatura (em escala Kelvin) e A, B e C são constantes empíricas adimensionais $(\mathrm{A}=23,224 ; \mathrm{B}=3841,22 ; \mathrm{C}=$ -45,0) [21, 22]. A Fig. 3c mostra a evolução da pressão de vapor da água em função da temperatura e a faixa correspondente de resistência mecânica típica para concretos refratários verdes (medida por compressão diametral). Dependendo da taxa de aquecimento utilizada, da velocidade de formação do vapor, da capacidade da estrutura em liberá-lo para a superfície e da resistência mecânica do concreto, o estágio de ebulição pode chegar a 
seu fim sem maiores problemas, em geral em temperaturas da ordem de $250-300^{\circ} \mathrm{C}$ (Fig. 2e1). No entanto, é comum que, durante a ebulição, a pressurização do vapor atinja valores da ordem dos limites de resistência mecânica do concreto. Essa pressurização é imposta aos concretos de modo similar à compressão isostática, porém de sentido inverso, ou seja, tração tri-axial (Fig. 2e2). Devido à sensibilidade natural dos materiais cerâmicos às forças de tração e à ausência de mecanismos de deformação na faixa de temperatura em que a secagem ocorre, os níveis de tensão necessários para romper o material podem ser facilmente superados pela pressão de vapor (Fig. 2e2). Nesse momento, se não houver algum mecanismo de alívio da pressão (com a ação dos aditivos de secagem), uma fratura frágil ocorre no material e as partes fraturadas são expelidas com violência. Enquanto peças pequenas podem ser totalmente destruídas pelas explosões de secagem, em corpos maiores e mais espessos, as explosões de secagem ocorrem inicialmente em profundidades inferiores a $10 \mathrm{~cm}$ em relação à superfície do concreto [15]. Se o material não for removido ou o aquecimento desligado, após uma primeira explosão ou lascamento, uma nova área ainda úmida é exposta a um elevado gradiente térmico, com grande probabilidade de ocorrência de novas e mais violentas explosões.

Uma vez superado os estágios de evaporação e ebulição, a secagem entra em sua fase final correspondente à decomposição de fases hidratadas dos ligantes hidráulicos utilizados (Figs. 2e1 e 3a) [21]. Sinais claros que podem ser utilizados para identificar o fim dessas etapas são a diminuição da velocidade de perda de massa (Fig. 3a) e aquecimento da superfície e o aumento da temperatura nas camadas mais internas do material (Fig. 3b) [22]. Dependendo da quantidade de ligante empregada, a decomposição de compostos hidratados, em geral, é superada sem maiores riscos de explosão devido à baixa velocidade do processo e à pouca quantidade de água remanescente na estrutura. Por volta de $350-400{ }^{\circ} \mathrm{C}$ a grande parte dos hidratos formados a partir dos cimentos de aluminato de cálcio e aluminas hidratáveis já se decompôs, embora a decomposição de certas fases (como hidróxidos de magnésio em concretos magnesianos) tenha sido observada até por volta de $600{ }^{\circ} \mathrm{C}$ [21].

\section{ADITIVOS DE SECAGEM}

\section{Pó de alumínio}

Os primeiros registros da utilização de pó de alumino (e outros pós metálicos como silício e magnésio) sugerem que essa aplicação tenha se derivado de seu uso como antioxidante em refratários pré-moldados contendo carbono, principalmente por refrataristas japoneses, a partir da década de 1980 [11, 12, 23, 24]. O pó de alumínio pode ser facilmente misturado a seco com as outras matérias primas da formulação e, após alguns minutos, começa a reagir com a água do concreto segundo a expressão:

$$
\mathrm{Al}+3 \mathrm{H}_{2} \mathrm{O}=\mathrm{Al}(\mathrm{OH})_{3}+\frac{3}{2} \mathrm{H}_{2}
$$

e seu mecanismo de atuação na secagem dos concretos está baseado em dois importantes efeitos dessa reação (Fig. 4) $[23,24]$. O primeiro e mais importante é a liberação de uma

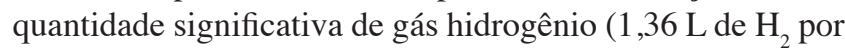
$\mathrm{g}$ de $\mathrm{Al}$ ). Como, em geral, a evolução de hidrogênio ocorre simultaneamente ao enrijecimento do concreto, a formação de pequenas bolhas de hidrogênio, que tendem a migrar para a superfície do material, gera pequenos canais permeáveis interligando a porosidade oclusa da matriz. Com a evolução do gás, uma quantidade significativa de vapor de água é arrastada com ele, iniciando o processo de secagem antes mesmo do fim da etapa de cura do material. O segundo efeito diz respeito ao elevado consumo de água que acompanha a formação de hidróxido de aluminio $\left(\mathrm{Al}(\mathrm{OH})_{3}\right)$. Com isso, uma parte significativa da água não combinada com os ligantes (e ainda não retirada com a evolução de hidrogênio) deixa de ser removida durante os estágios de evaporação (25$\left.110^{\circ} \mathrm{C}\right)$ e ebulição $\left(110-300^{\circ} \mathrm{C}\right)$ e é deslocada para o estágio de desidratação (acima de $300{ }^{\circ} \mathrm{C}$ ). A combinação desses efeitos resulta na drástica redução na quantidade de água a ser removida nos estágios iniciais da secagem, permitindo

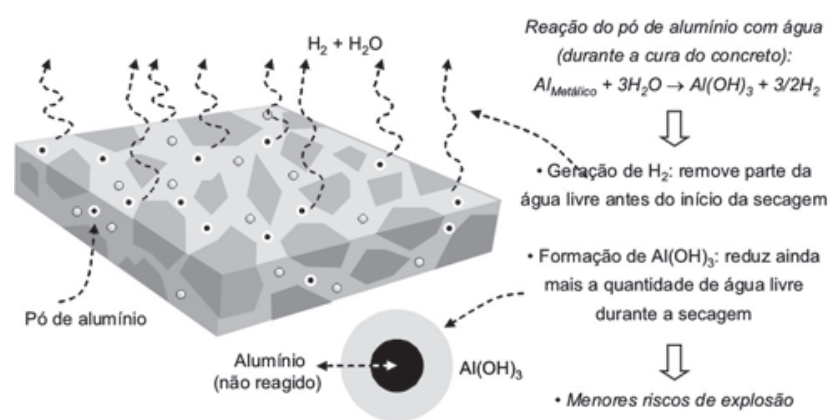

Figura 4: Mecanismo de atuação do pó de alumino na secagem de concretos refratários [23, 24].

[Figure 4: Aluminum powder as drying additive in refractory castables [23, 24].]

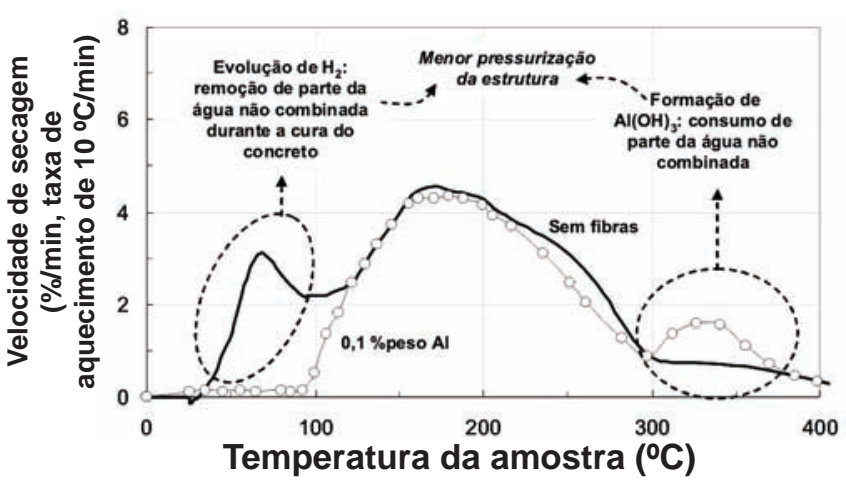

Figura 5: Velocidade de secagem para concretos refratários contendo pó de alumínio [24, 25].

[Figure 5: Drying rate profile for aluminum powder containing refractory castables [24, 25].] 
que os níveis de pressurização e os riscos de explosão sejam reduzidos (Fig. 5).

Para que a adição de pó de alumínio favoreça o processo de secagem dos concretos, alguns pontos importantes devem ser observados. Uma característica da utilização do pó de alumínio é que o aumento de porosidade e permeabilidade verificado após a ação do pó de alumínio é pouco significativo quando comparado a outros mecanismos como a adição de fibras poliméricas e incorporadores de ar e o aumento do teor de água da formulação, por exemplo [24]. Esse efeito ocorre pois como o concreto ainda não se encontra totalmente enrijecido, à medida que a evolução do gás acaba, as paredes dos canais formados colapsam sobre o próprio peso e a estrutura inicial de baixa permeabilidade é reconstruída. Esse ponto pode ser encarado como uma importante vantagem para sistemas que necessitem de baixa permeabilidade durante o uso para minimizar a oxidação de carbono ou infiltração de agentes corrosivos, por exemplo. Para que o mecanismo funcione dessa forma, é importante que a evolução de gás e o enrijecimento do concreto ocorram simultaneamente, pois do contrário: a) a evolução prematura de gás poderia remover uma quantidade excessiva de água impedindo a hidratação do ligante; b) a evolução tardia do gás não formaria os canais permeáveis, pressurizando a estrutura de forma similar à que ocorre durante a secagem [24], levando muitas vezes ao inchamento do material.

A cinética de evolução de hidrogênio pode ser modificada por meio do ajuste das características físicas do pó de alumínio e do ambiente onde a reação ocorre. Quanto maiores a área superficial das partículas de alumínio e a temperatura do sistema, maior sua reatividade (mais rápida a reação e maior a quantidade de hidrogênio e hidróxido de alumínio geradas) [23]. Por outro lado, recobrimentos superficiais à base de parafina podem reduzir consideravelmente a velocidade de reação. Dispersantes (ácido cítrico e poli (acrilato de sódio)), ligantes hidráulicos (cimentos de aluminato de cálcio e aluminas hidratáveis) ou coloidais (sois de sílica e alumina) e óxido de magnésio, também podem afetar consideravelmente a reação de hidratação do alumínio por meio de variações de $\mathrm{pH}$ e da concentração de íons $\mathrm{Ca}^{2+}$, $\mathrm{Al}^{3+}$ e $\mathrm{HSiO}^{3+}$. Estudos detalhados desses aspectos podem ser encontrados [26-28].

Devido à sua natureza altamente explosiva, a evolução de hidrogênio durante a cura dos concretos têm sido como uma constante preocupação por parte dos produtores e usuários de concretos refratários. Assim, é importante que a cura dos concretos e os estágios iniciais de sua secagem seja conduzidos em ambiente ventilado para evitar acúmulo de gás.

\section{Fibras poliméricas}

A adição de fibras poliméricas, principalmente as de polipropileno (PP), recebeu seus primeiros pedidos de patente nos Estados Unidos no final da década de 1970, quando as fibras desse material se tornaram comercialmente disponíveis. No entanto, a adição de materiais orgânicos (cascas de cereais, serragem e farinhas em geral) como forma de incorporar porosidade a materiais cerâmicos tem registros anteriores à segunda guerra mundial [25].

O mecanismo de atuação das fibras poliméricas está associado principalmente ao aumento controlado da permeabilidade do concreto após a fusão e degradação das fibras [29-32]. Como o pó de alumínio, as fibras podem ser misturadas a seco com as outras matérias primas que compõe a formulação e durante a moldagem e enrijecimento do concreto, formam uma rede tridimensional. Essa rede conecta as várias regiões da estrutura dos concretos, como as interfaces permeáveis matriz-agregado, a porosidade oclusa da matriz, além dos próprios canais formados pelas fibras (Fig. 6) [32]. Quando o aquecimento inicial do concreto começa, diversas transformações térmicas ocorrem nas fibras, permitindo que o vapor pressurizado escoe através dos canais permeáveis [33-35]. O sucesso desse mecanismo de aumento de permeabilidade em reduzir os riscos de explosão durante a secagem está baseado em dois requerimentos principais: o primeiro está associado ao nível do aumento de permeabilidade gerado e, conseqüentemente, à quantidade de vapor de água pressurizado que pode ser escoada em um determinado intervalo de tempo (maiores níveis de permeabilidade podem remover maior quantidade de vapor e vice-versa) [36, 37]; o segundo diz respeito à faixa de temperatura em que o mecanismo das fibras irá atuar em relação à pressão do vapor prevista pela equação de Antoine (equação A) [34, 35]. Como níveis de pressão de vapor bastante próximos à resistência mecânica dos concretos podem ser observados em temperaturas pouco acima do ponto de ebulição da água, quanto menor for a temperatura do aumento de permeabilidade, menor a pressurização da estrutura e os riscos de explosão.

Elevados níveis de permeabilidade podem ser atingidos

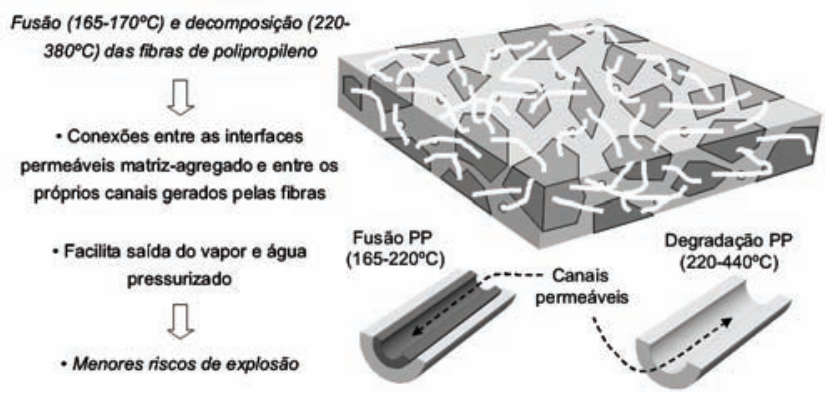

Figura 6: Mecanismo de atuação das fibras poliméricas (fibras de polipropileno, neste caso) $[29,31]$.

[Figure 6: Polypropylene fibers as drying additive in refractory castables [29, 31].]

aumentando-se a quantidade de fibras adicionadas à formulação $[30,34,38]$ ou considerando-se uma fração volumétrica fixa, otimizando sua geometria (Fig. 7a) [3638]. O primeiro caso apresenta alguns limites práticos referentes ao aumento expressivo da porosidade do material, que pode limitar seu desempenho durante o uso (valores máximos da ordem de $0,5 \%$ volume do concreto seco). $\mathrm{O}$ 
segundo está associado à grande variedade de tipos de fibras comercialmente disponíveis e, devido a isso, aos critérios de seleção baseados nos níveis de permeabilidade gerados durante o tratamento térmico. Mudanças no comprimento e diâmetro das fibras afetam o número total de fibras e, portanto, de canais permeáveis formados, como mostrado na Fig. 8. Fibras muito curtas (comprimento $<2 \mathrm{~mm}$ ) tendem a formar canais de pouco alcance que não alteram significativamente a permeabilidade e comportamento de secagem dos concretos. Já as muito grossas (diâmetro > $100 \mu \mathrm{m}$ ), encontram-se em pequeno número e, apesar de formarem canais muito permeáveis, também não atuam favoravelmente [36].

Para concretos autoescoantes, os maiores aumentos de

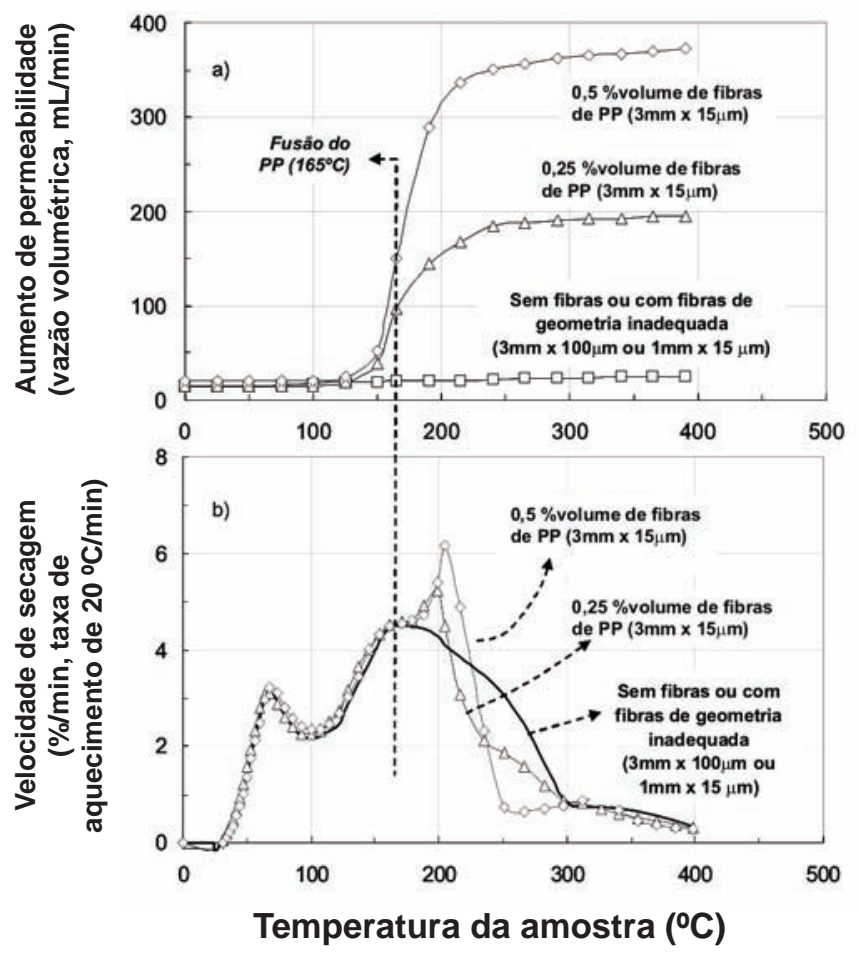

Figura 7: Comportamento a) fluidinâmico e b) de secagem de concretos refratários contendo fibras de polipropileno (diferentes teores e geometrias) $[25,38]$.

[Figure 7: a) fluidynamic and b) drying behavior for polypropylene fibers containing castables [25, 38].]

permeabilidade e benefícios na secagem foram obtidos com fibras finas (diâmetros da ordem de 15-50 $\mu \mathrm{m}$ ) e longas (comprimento inicial entre 2 e $6 \mathrm{~mm}$ ), que geram grande quantidade de canais altamente permeáveis, adicionadas em um teor volumétrico entre 0,2 e $0,4 \%$ (0,05-0,1\%peso, para concretos de alta alumina). Essa geometria também minimiza as dificuldades que a adição das fibras pode introduzir nas etapas de mistura e bombeamento dos concretos: fibras com comprimentos acima dessa faixa tendem a ancorar as partículas do concreto aumentando significativamente a energia necessária para a mistura [37]. Outras classes de

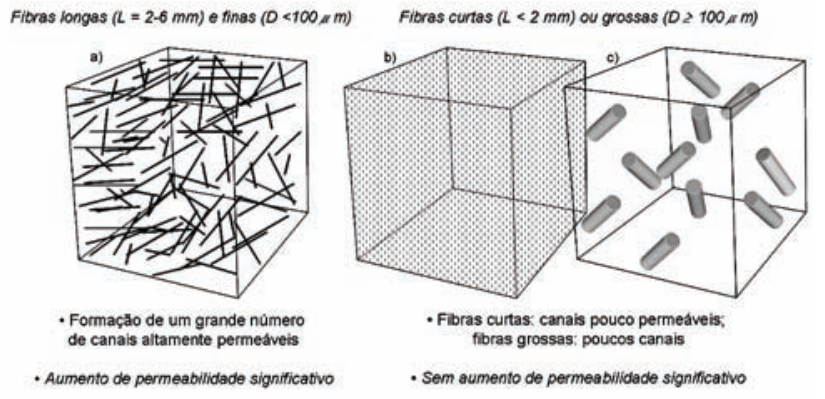

Figura 8: Representação da distribuição espacial de fibras com diferentes geometrias (para uma mesma fração volumétrica adicionada à formulação) [36].

[Figure 8: Schematic view of the fibers of different geometry dispersed in the castable matrix, considering the same given fiber content [36].]

concretos, como os bombeáveis e vibráveis, por possuírem diferentes estruturas, apresentam maiores níveis de permeabilidade e, devido a isso, outras relações otimizadas entre diâmetro e comprimento das fibras [32].

Uma vez definidas geometrias das fibras que maximizem o aumento de permeabilidade, com uma fração volumétrica fixa de polímero e para uma dada formulação de concreto, a faixa de temperatura em que ele ocorre se torna o próximo importante critério de seleção e está diretamente relacionada à composição das fibras. No caso de fibras produzidas a base de polímeros termoplásticos, como o polipropileno, é a fusão do polímero $\left(165-170{ }^{\circ} \mathrm{C}\right)$, seguida de sua degradação térmica $\left(220-380^{\circ} \mathrm{C}\right)$, que causam uma drástica redução na viscosidade do material $[39,40]$, permitindo que o vapor pressurizado deforme a massa polimérica e escoe através dos canais permeáveis [31]. Fibras com menor susceptibilidade à temperatura, como as produzidas a partir do poli(etileno tereftalato) (ou PET, temperatura de fusão $235^{\circ} \mathrm{C}$ ), não apresentam um bom desempenho na secagem, embora possam levar a aumentos de permeabilidade equivalentes àqueles gerados pelas de polipropileno [34, 35]. Por outro lado, o recente desenvolvimento de fibras poliméricas especificamente projetadas para atuarem como aditivo de secagem, conhecidas como fibras de alto desempenho e produzidas a partir de uma cuidadosa seleção de polímeros e copolímeros de baixo ponto de fusão, permitiu que elevados aumentos de permeabilidade fossem obtidos abaixo de 100 ${ }^{\circ} \mathrm{C}$, aumentando significativamente a velocidade de secagem do concreto (Fig. 9) [41].

Algumas fibras naturais também apresentam outro mecanismo de aumento de permeabilidade de grande eficiência baseado na redução da secção transversal (Fig. 9a) [42]. Após a extração, a retirada dos fluídos que preenchiam as fibras causa uma retração significativa em seu diâmetro. Durante a mistura, o contato das fibras com a água permite que a geometria original expandida seja recuperada e seja preservada pelo enrijecimento do concreto [43]. Nos estágios iniciais da secagem (em alguns casos, mesmo em temperatura ambiente) uma nova contração diametral 
ocorre, levando à formação de canais permeáveis ao redor das fibras que, como nos casos anteriores, facilitam a saída do vapor pressurizado (Fig. 9b). A utilização das fibras naturais como aditivos de secagem conta ainda com o custo reduzido desses materiais e com a grande disponibilidade de tipos e fornecedores [42].
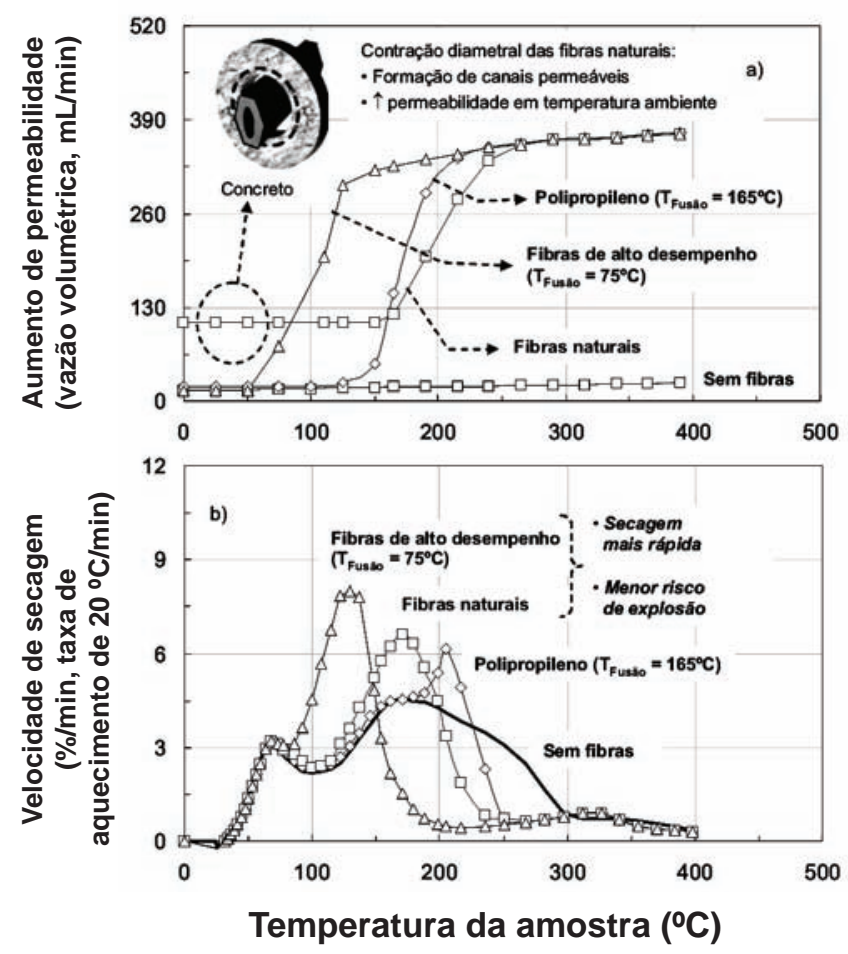

Figura 9: Comportamento a) fluidinâmico e b) de secagem de concretos refratários contendo fibras de alto desempenho [25, 41] e naturais [25, 42].

[Figure 9: a) Fluidynamic and b) drying behavior of high performance polymeric fibers [25, 41] and natural fibers [25, 42] containing refractory castables.]

\section{CONSIDERAÇÕES FINAIS}

Os aditivos de secagem apresentados neste trabalho podem tornar o processo de secagem de concretos refratários mais seguro e, simultaneamente, com menor período de lucro cessante. Para que atuem de forma adequada, certos requerimentos e especificações devem ser observados. Para as formulações com pó de alumínio (teores entre 0,05$0,1 \%$ peso), a velocidade de evolução de hidrogênio deve ser controlada para que ela ocorra junto com o início da pega do ligante. Variações em parâmetros como a temperatura de cura, granulometria do pó e tratamentos superficiais podem ser utilizadas para ajustar essa condição. É importante que as etapas de cura e secagem de concretos contendo pó de alumínio sejam realizadas em ambiente ventilado, para evitar o acúmulo de gás e explosões. O tipo de fibras poliméricas empregado nas formulações de concreto deve ser cuidadosamente escolhido para gerar um grande aumento de permeabilidade, na menor temperatura possível. Teores da ordem de 0,05-0,1\%peso, de fibras finas $(8-30 \mu \mathrm{m}$ de diâmetro) e longas (2-6 mm de comprimento) maximizam o aumento de permeabilidade sem afetar significativamente o comportamento de mistura dos concretos. Em relação à composição das fibras, aquelas feitas a partir de polipropileno e as naturais são produtos comerciais e apresentam um bom desempenho; as fibras de alto desempenho, desenvolvidas pelos autores deste trabalho, ainda se encontram em processo de patenteamento.

\section{AGRADECIMENTOS}

À Fundação de Apoio à Pesquisa no Estado de S. Paulo (FAPESP), à Alcoa Alumínio e à Magnesita S.A. pelo suporte fornecido a este trabalho.

\section{REFERÊNCIAS}

[1] W. E. Lee, R. E. Moore, J. Am. Ceram. Soc. 81, 6 (1998) 1385-1410.

[2] D. O. McCreight, Am. Ceram. Soc. Bull. 27, 7 (1948) 257-261.

[3] J. F. Wygant, W. L. Bulkley, Am. Ceram. Soc. Bull. 33, 8 (1954) 233-239.

[4] J. F. Wygant, M. S. Crowley, Am. Ceram. Soc. Bull. 43, 1 (1964) $1-5$.

[5] M. S. Crowley, R. Johnson, Am. Ceram. Soc. Bull. 51, 2 (1972) 171-176.

[6] C. M. Peret, J. A. Gregolin, L. I. L. Faria, V. C. Pandolfelli, Refrac. Appl. News 12, 1 (2005) 10-14.

[7] W. H. Gitzen, L. D. Hart, Am. Ceram. Soc. Bull. 40, 8 (1961) 503-510.

[8] G. V. Givan, L. D. Hart, R. P. Heilich, G. McZura, Am. Ceram. Soc. Bull. 54, 8 (1975) 710-713.

[9] R. E. Moore, J. D. Smith, W. L. Headrick, T. P. Sander, "Monolithic dewatering theory testing and practice: new challenges", Proc. 32 $2^{\text {th }}$ Annual Symp. Refractories, Saint Louis, EUA (1996) 1-19.

[10] Z. Gong, A. S. Mujumdar, J. Am. Ceram. Soc. 79, 6 (1996) 1649-1658.

[11] T. Taizo, "Monolith refractory compositions", US Patent n. 4120734 (1978).

[12] K. Wefers, "Oxides and hydroxides of aluminum", Technical Report 19, Alcoa Laboratories, Pittsburgh, EUA (1987) 64-71.

[13] P. H. Havranek, Am. Ceram. Soc. Bull. 62, 2 (1983) 234-243.

[14] T. R. Kleeb, J. A. Caprio, "Properties and service experience of organic fiber-containing monoliths", in R. Fisher (Ed.), Advances in Ceramics, Am. Ceram. Soc., EUA (1985).

[15] A. Nishikawa, "Technology of monolithic refractories", Plibrico Co. Ltd., (1984) 134-183.

[16] I. R. Oliveira, A.R. Studart, R. G. Pileggi, V. C. Pandolfelli, "Dispersão e empacotamento de partículas", Fazendo Arte Editorial (2000) 119-137.

[17] G. W. Scherer, J. Am. Ceram. Soc. 73, 1 (1990) 3-14. 
[18] J. S. Reed, "Principles of ceramic processing", John Wiley \& Sons Inc. (1995) 545-561.

[19] E. J. Garboczi, D. P. Bentz, Adv. Cem. Bas. Mater. 6 (1997) 99-108.

[20] M. D. M. Innocentini, C. Ribeiro, L. R. M. Bittencourt, V. C. Panfolelli, J. Am. Ceram. Soc. 84, 11 (2001) 26962698.

[21] M. D. M. Innocentini, F. A. Cardoso, M. M. Akyioshi, V. C. Pandolfelli, J. Am. Ceram. Soc. 86, 7 (2003) 11461148.

[22] M. D. M. Innocentini, M. F. S. Miranda, F. A. Cardoso, V. C. Pandolfelli, J. Am. Ceram. Soc. 86, 9 (2003) 15001503.

[23] M. D. M. Innocentini, L. A. Nascimento, A. E. M. Paiva, L. R. M. Bittencourt, B. A. Menegazzo, V. C. Pandolfelli, Am. Ceram. Soc. Bull. 82, 6 (2003) 45-55.

[24] M. D. M. Innocentini, L.A. Nascimento, A. E. M. Paiva, L. R. M. Bittencourt, B. A. Menegazzo, V. C. Pandolfelli, Am. Ceram. Soc. Bull. 82, 8 (2003) 1-5.

[25] R. Salomão, Fibras poliméricas e a secagem de concretos refratários, Tese de Doutorado, UFSCar, S. Carlos, SP (2005) 85-87.

[26] A. R. Studart, I. R. Oliveira, M. D. M. Innocentini, V. C. Pandollfelli, Am. Ceram. Soc. Bull. 83, 9 (2004) 91019107.

[27] A. R. Studart, M. D. M. Innocentini, I. R. Oliveira, V. C. Pandolfelli, J. Eur. Ceram. Soc. 25 (2005) 3135-3143.

[28] S. Zhang, S. Hashimoto, W. E. Lee, J. Am. Ceram. Soc. 88, 4 (2005) 1057-1059.

[29] D. P. Bentz, Am. Conc. Inst. Mater. J. 97, 3 (2000) 351359.

[30] P. Kalifa, G. Chéné, C. Gallé, Cem. Conc. Res. 31 (2001) 1487-1499.
[31] R. Salomão, V. C. Pandolfelli, J. Tec. Asssoc. Refr. Japan 24, 2 (2004) 83-87.

[32] R. Salomão, V. C. Pandolfelli, Ceram. Int.34, 1 (2008)173-180..

[33] M. D. M. Innocentini, C. Ribeiro, R. Salomão, L. R. M. Bittencourt, V. C. Pandolfelli, J. Am. Ceram. Soc. 85, 8 (2002) 2110-2112.

[34] M. D. M. Innocentini, R. Salomão, C. Ribeiro, L. R. M. Bittencourt, V. C. Pandolfelli, Am. Ceram. Soc. Bull. 81, 7 (2002) 34-38.

[35] M. D. M. Innocentini, R. Salomão, C. Ribeiro, L. R. M. Bittencourt, V. C. Pandolfelli, Am. Ceram. Soc. Bull. 81, 8 (2002) 65-68.

[36] R. Salomão, A. M. Zambon, V. C. Pandolfelli, Am. Ceram. Soc. Bull. 85, 4 (2006) 9201-9205.

[37] R. Salomão, V. G. Domiciano, V. C. Pandolfelli, Am. Ceram. Soc. Bull. 85, 5 (2006) 21-25.

[38] R. Salomão, L. R. M. Bittencourt, V. C. Pandolfelli, "Advances on the understanding on the role of the polymeric fibers as drying additives for refractory castables", Proc. Unified Int. Technical Conf. Refractories - UNITECR'05, Orlando, EUA (2005) 816-820.

[39] E. Andreassen, J. Appl. Pol. Sci. 57 (1995) 1075-1084. [40] Y. Nakajima, "Advanced fiber spinning technology", Woodhead Publ. (1994) 25-54.

[41] R. Salomão, L. R. M. Bittencourt, V. C. Pandolfelli, Am. Ceram. Soc. Bull. 87 (2008) 9101-9106.

[42] R. Salomão, C. S. Isaac, V. G. Domiciano, R. G. Pileggi, V. C. Pandolfelli, Am. Ceram. Soc. Bull. 83, 1(2004) 92019206,.

[43] A. K. Bledzki, J. Gassan, Prog. Pol. Sci. 24 (1999) 221274.

(Rec. 13/08/2007, Ac. 26/10/2007) 